\title{
Eliminating Fastener Thermal Bridging in Low Slope Roofs: Energy Efficiency Savings versus Installation Costs
}

\author{
Thomas J. Taylor \\ Building and Roofing Science, GAF, Parsippany, USA \\ Email: Thomas.Taylor@gaf.com
}

How to cite this paper: Taylor, T.J. (2020) Eliminating Fastener Thermal Bridging in Low Slope Roofs: Energy Efficiency Savings versus Installation Costs. Open Journal of Energy Efficiency, 9, 94-110. https://doi.org/10.4236/ojee.2020.92007

Received: March 3, 2020

Accepted: April 26, 2020

Published: April 29, 2020

Copyright $\odot 2020$ by author(s) and Scientific Research Publishing Inc. This work is licensed under the Creative Commons Attribution International License (CC BY 4.0).

http://creativecommons.org/licenses/by/4.0/

\begin{abstract}
Low-slope roofing assemblies include a wide range of insulation and single ply membrane attachment methods. Previous studies have shown that mechanical attachment using metal fasteners leads to significant thermal bridging and consequent loss of insulation value and reduction of long term thermal efficiency. This study calculates the costs associated with mechanical attachment in terms of lost insulation value, increased long-term energy costs, and the material and labor costs associated with installation of these common systems. Energy efficiency reductions using metal fasteners were modeled for eight US cities in a range of climate zones. From the data, it was possible to calculate target costs (labor plus materials) that would make adhered systems cost effective. There are many options available to adhere single ply roof system components, such as solvent-based adhesives and low-rise urethane foams, together with different application approaches such as broom, spray, and ribbon methods. The cost targets derived in this study can help optimize the use of such materials and application methods such that the thermal bridging due to fasteners could be substantially reduced or eliminated.
\end{abstract}

\section{Keywords}

Energy Efficiency, Thermal Bridging, Roof Assemblies

\section{Introduction}

Commercial buildings include a variety of building types such as offices, hospitals, schools, police stations, places of worship, warehouses, hotels, and shopping malls. Different commercial building activities have unique energy needs, but as a whole, space heating accounted for about $25 \%$ of the total energy use in com- 
mercial buildings in the US during 2012, the latest year for which such data is available [1]. Improving energy conservation in buildings has long been recognized as an important approach to reduce energy consumption and greenhouse gas emissions. Many governments and utilities have mandates to encourage energy conservation in buildings, and city and state jurisdictions have increasingly adopted more stringent building energy efficiency standards. Building envelope thermal performance is a critical consideration for reducing space heating loads and will play an increasingly important role as authorities strive for lower energy consumption in buildings [2].

It is evident that thermal performance of the building envelope can be significantly affected by thermal bridging [3]. Thermal bridges are localized areas of high heat flow through walls, roofs, and other insulated building envelope components. Thermal bridging is caused by conductive elements that penetrate and/or bypass thermal insulation, and/or misaligned planes of thermal insulation. These paths allow heat flow to bypass the insulating layer, and reduce the effectiveness of the insulation.

Low-slope roofs in the US typically comprise a waterproof membrane installed on top of layers of polyisocyanurate foam insulation, with this assembly being attached to a fluted steel deck. These "insulated metal deck" roofing assemblies can be mechanically-attached through the use of steel screws and plates using custom-sized washers, or attached through using various adhesives. Combinations of these approaches are also used, whereby some layers are adhesively-attached and others mechanically-attached. Selecting which attachment method to use depends on factors such as required wind uplift resistance, construction costs, aesthetics, and system warranty.

As will be discussed, mechanical attachment of low-slope roofing components can lead to significant thermal bridging. This study builds on prior work to closely examine the long-term economic costs of thermal bridging in low slope roof assemblies, resulting from reduced energy efficiency and lost thermal insulation value. The US has different climate zones where some buildings are dominated by heating costs and in others by cooling costs. Electric heat can also be used in certain parts of the US where electric demand charges are common [4]. These two factors can significantly increase the cost of reduced energy efficiency. Reductions in thermal performance due to bridging can also have a compound effect on building energy efficiency by influencing specification of heating, ventilation, and air conditioning (HVAC) systems.

This study examines the true cost of mechanically attached thermoplastic single-ply roof membranes by including the effects of thermal bridging. It seeks to quantify economic targets where adhesively-attached systems could be used without increased costs; analyzing the total cost of thermal bridging in terms of lost insulation value, cost of fasteners, installation labor, and the reduction of long term energy efficiency. Today, comparisons between mechanically-attached and adhesively-attached approaches are made in terms of initial material and labor costs. This analysis may allow decisions to be made in terms of the overall 
cost, including lost insulation value and reduced long term energy efficiency.

This study considers differences between the design and effective insulation values (RSI, $\mathrm{m}^{2} \mathrm{~K} / \mathrm{W}$ or R-value, ${ }^{\circ} \mathrm{F} \mathrm{ft}{ }^{2} \mathrm{hr} / \mathrm{Btu}$ ) of a common low-slope roofing assembly. Such roofs are considered to have a slope of less than 2:12 (9.46 degrees). The aim was to evaluate differences caused by attachment methods commonly used in the roofing industry. As noted previously [5] [6], design RSI refers to the RSI intended by the architect or other design professional. The effective RSI refers to the insulation value that is actually achieved after practical matters, such as installation methods, are taken into account.

This study, the effect of mechanically fastening a roof assembly with screws and plates on the difference between the design RSI intended by the design professional, and the effective RSI after actual construction. It is important to note that in this study, RSI refers either to the thermal resistance of the material or entire assembly, depending on context. A prior study by Taylor, Willits, Hartwig, and Kirby did not account for labor costs associated with various roof assembly practices [5] [6]. That first study showed that some adhered systems had the potential to significantly reduce thermal bridging in an economic way. This present study provides a closer examination of installation costs and guidance as to targets that could cost effectively make specific systems more energy efficient.

\section{Background}

\subsection{Low-Slope Roofing Assemblies}

This study analyzed roofing assemblies consisting of a fluted steel deck, two layers of polyisocyanurate foam insulation (commonly referred to as polyiso or PIR), and a thermoplastic single-ply membrane. Examples of the membrane include flexible polyvinyl chloride (PVC) and thermoplastic polyolefin (TPO). Figure 1 shows a schematic to illustrate the general concept.

In mechanically-attached thermoplastic systems, the polyiso insulation is attached with screws and plates applied through the insulation boards. The membrane is then rolled out over the insulation and also fastened with screws and plates along the edge. The next roll overlaps the fasteners and the seam is fused using hot air. For adhered systems, the membrane is not fastened with screws

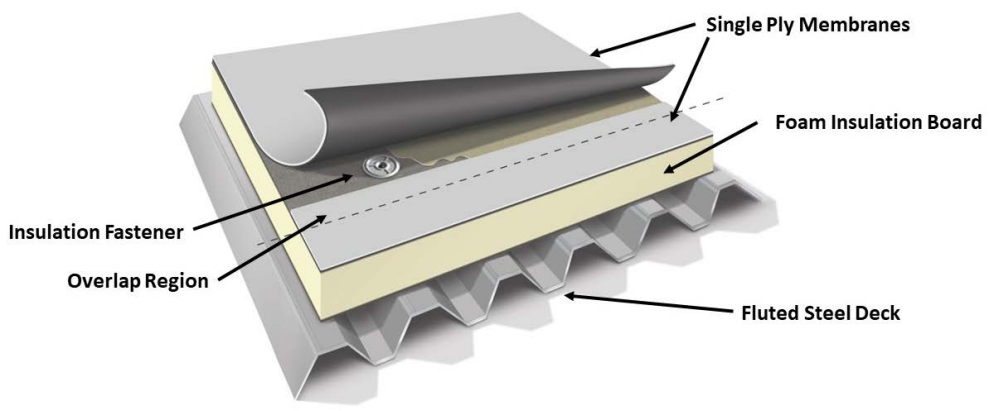

Figure 1. Schematic of a single ply, insulated steel deck roofing assembly. Note, in the US, foam insulation is normally applied as two layers of boards with staggered and offset joints. 
but is attached to the insulation board beneath it using an adhesive. The insulation boards can also be adhered or fastened with screws and plates. The bottom insulation boards are typically always mechanically-fastened.

For adhered systems, there are a plethora of options including solvent- and water-based adhesives that are applied using rollers or brooms, or spray-applied depending on their properties. Low-rise urethane foams can also be used and applied as coarse sprays or in a ribbon format. Adhesives have varying coverage rates, depending on type and manufacturer. Also, there are variables such as solvent flash-off times and application temperature that make general material cost and labor estimates difficult to assess.

US building codes state such roofs consist of three zones (corner, field, and perimeter) for determining necessary fastener patterns to achieve required wind uplift resistance. These zones are shown schematically in Figure 2.

When mechanically-fastened, polyiso insulation is normally attached with a uniform fastener density regardless of roof zone, except in the case of inductively-welded plates. Such plates are coated with a thermoplastic resin that fuses to the membrane after installation via inductive heating. With inductive plates, screw and plate densities vary according to corner, perimeter, and field of the roof.

Mechanically-attached single-ply membranes have different fastener densities depending on the roof zone. These are achieved by using half width sheets along the roof perimeter, as indicated in Figure 3.

Fastener densities used in this study will be described later, but generally range between approximately $4.3 / \mathrm{m}^{2}\left(0.4 / \mathrm{ft}^{2}\right)$ for totally mechanically-attached systems to as low as $2.8 / \mathrm{m}^{2}\left(0.26 / \mathrm{ft}^{2}\right)$ for systems using adhesive for the membrane and top layer of insulation.

\subsection{Thermal Bridging Due to Roofing Fasteners}

An analysis by Burch, Shoback, and Cavanaugh found that metal fasteners reduced overall thermal resistance of insulated metal deck assemblies by $3 \%-8 \%$ depending on insulation thickness [7]. They used a finite difference model to analyze overall thermal resistance for assemblies using 50 fasteners per $5.38 / \mathrm{m}^{2}$ $\left(100 \mathrm{ft}^{2}\right)$.

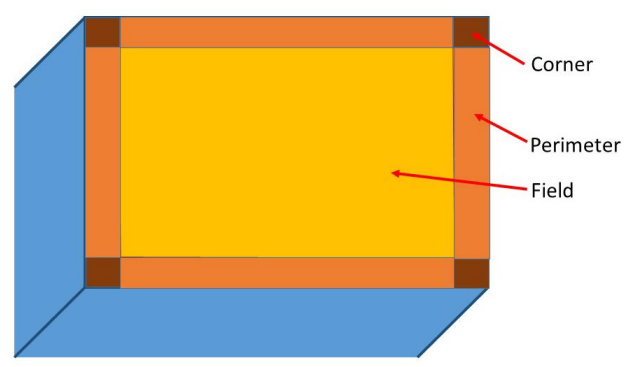

Figure 2. A rectangular roof showing the three zones for which various fastener densities are specified for achieving the requisite wind uplift performance-field, perimeter, and corner. 


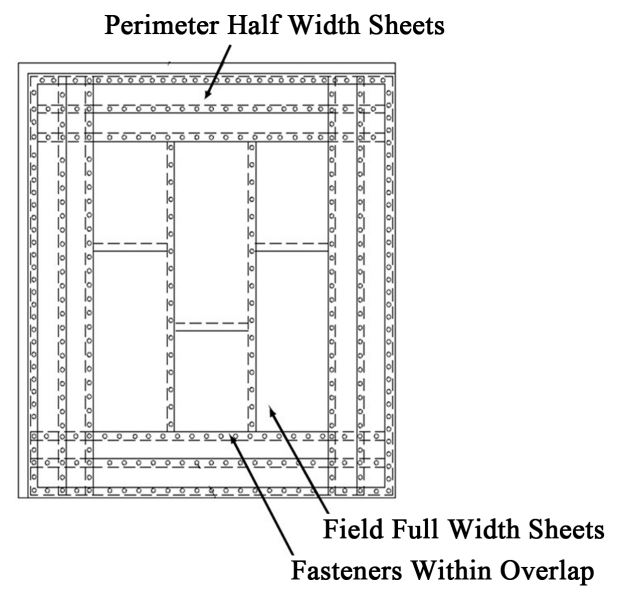

Figure 3. Schematic showing single-ply membrane arrangement and mechanical fastening.

Olson, Saldanha, and Hsu modelled the impact of metal fasteners and other penetrations in single-ply roof systems [8]. Heat transfer in three zones of a model rectangular roof (field, corner, and perimeter), with \#12 insulation fasteners (shanked $5.56 \mathrm{~mm}$ (7/32 in) diameter screws) and $7.6 \mathrm{~cm}$ (3 in) metal plates was examined. Their data was recalculated in a previous study [5] [6], with the resulting relationship between percent reduction from design RSI and fastener density being as shown in Figure 4.

Singh, Gulati, Srinivasan, and Bhandari carried out a similar analysis, but considered system U-factor (i.e., the overall coefficient of heat transfer, $\mathrm{W} /\left(\mathrm{m}^{2} \cdot \mathrm{K}\right)$ or $\mathrm{Btu} /\left(\mathrm{hr} \mathrm{ft}^{2}{ }^{\circ} \mathrm{F}\right)$, and modeled based on temperatures within three climate zones represented by Orlando, FL, Atlanta, GA, and St. Paul, MN, US [9]. A total roof area of $929 \mathrm{~m}^{2}\left(10,000 \mathrm{ft}^{2}\right)$ was assumed and a higher overall fastener density compared to Olson, Saldanha, and Hsu. The reduction to an effective RSIfrom designed RSI was found to be about 35\%. For a roof having a fastener density of $10.78 / \mathrm{m}^{2}\left(1.0 / \mathrm{ft}^{2}\right)$ Singh, Gulati, Srinivasan, and Bhandari calculated a loss from the design RSI of $32 \%$.

\subsection{Economic Modeling of Lost Thermal Resistance}

With modeled losses from designed RSI being potentially as high as approximately $35 \%$ designers considering using metal fasteners and plates for the attachment of both insulation and roof membranes may need to consider several implications, including:

- Initial installation costs-while mechanically-attached systems are generally regarded as lower cost compared to adhered systems, a simple analysis of construction material costs (i.e. screw versus adhesive costs) does not take into account lost insulation costs and long term energy efficiency.

- Design versus effective RSI (R-value) - while a designer may specify RSI 5.28 (R-30) for example, and the building owner pays for the equivalent amount of insulation board, the final effective RSI could be lower due to thermal bridging. That "lost" RSI carries an economic cost. 


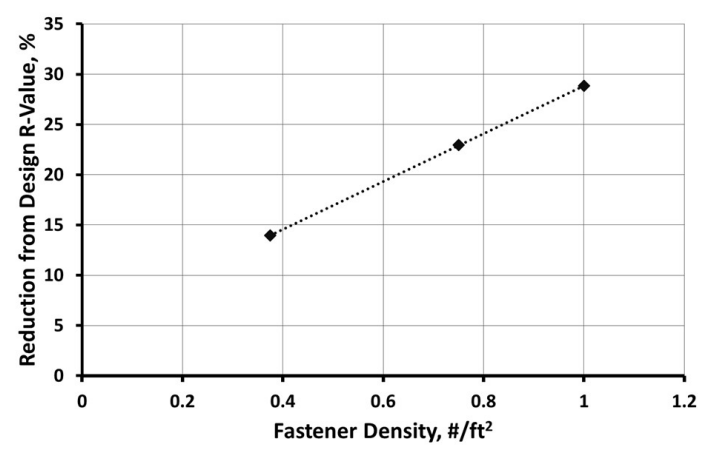

Figure 4. Analysis of the effects of insulation fastener configuration on insulation value results shown by Olson, Saldanha, and Hsu [8] to show percent reduction from design R-value $(y)$ as a function of overall roof fastener density $(x)$, where the straight line fit is expressed as $y=23.851 x+5.0192[5][6]$.

- Long term energy efficiency-as described earlier, thermal bridging reduces the insulation value therefore leading to lower long term energy efficiency. Space heating and cooling costs would then increase.

In the prior studies, Taylor, Willits, Hartwig, and Kirby modeled possible total costs for each of these categories for six different hypothetical roofing assemblies [5] [6]. The assemblies varied according to insulation and membrane attachment methods. Some assemblies included cover boards. Their modeling showed that on a material cost basis alone, totally mechanically-attached systems were the lowest cost systems. However, after considering the economic value of lost RSI together with the impact of long-term energy efficiency, some adhered systems appeared to be competitive. However, that prior study did not take into account labor costs which are an important differentiator between mechanically-attached versus adhered systems. Also, material costs were difficult to define due to various supply chains used. For example, for very large projects materials could be shipped directly to the job site, bypassing distribution. For smaller projects a contractor might purchase from distribution. However, large contractors operating on a regional or national basis sometimes purchase directly. Margins throughout the supply chain vary according to material volume. For all of these reasons, this study aims to provide target costs that would enable adhesively-attached systems to be competitive with mechanically-attached approaches.

\section{Methods and Analysis Inputs}

\subsection{Locations}

Eight US cities were selected, including Albany, NY, Chicago, IL, Fresno, CA, Fort Worth TX, Miami, FL, Nashville, TN, Newark, NJ, and Portland, OR, with the locations as indicated in Figure 5. The cities were selected to allow for a range of north-to-south climate data in populous regions of the country.

\subsection{General Description of the Roof Assemblies}

Building geometry was as described in previous studies with a roof area of 


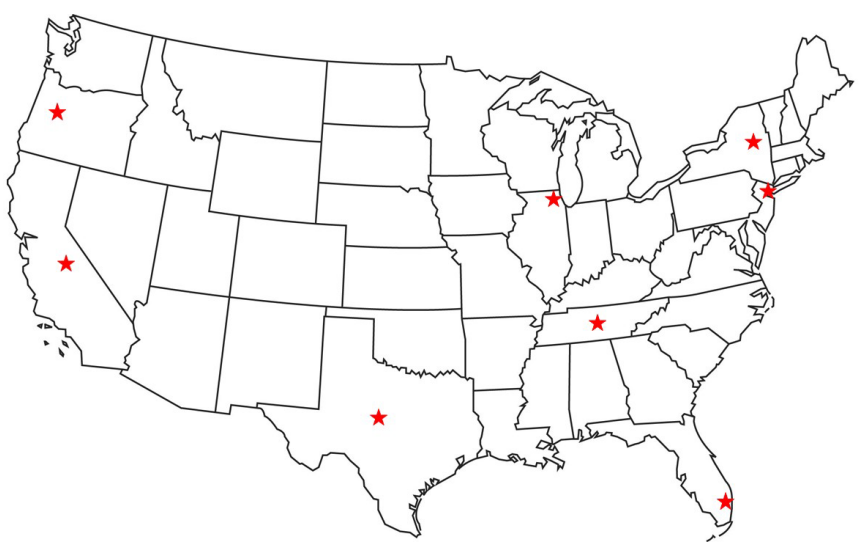

Figure 5. Map of the US showing the locations of the eight cities studied.

$11,613 \mathrm{~m}^{2}\left(125,000 \mathrm{ft}^{2}\right)$ [5] [6]. Building height was assumed to be less than 10.67 $\mathrm{m}$ (35 feet). This would be typical of a big box retail store, an example of which is shown in Figure 6.

The modelled roofs were assumed to be new installations, i.e., new construction or total roof replacement. A membrane width of $3.05 \mathrm{~m}(10 \mathrm{ft})$ was assumed, this being typical of single-ply membranes.

The US Cool Roof Rating Council reports independently-tested solar reflectance and emissivity values for unaged and three-year-exposed commercially-available roof membranes and coatings [10]. Three-year aged solar reflectance of 68 and emittance of 83 values, which are typical of a thermoplastic membrane such as TPO, were used.

A design insulation value of RSI 5.28 (R-30) was used, this being the average of the insulation requirements in the 2018 IECC for US climate zones [11]. Installation of two-layer polyiso foam insulation was assumed, as required by that code. Individual layers of polyiso are not required to be equivalent in thickness and in practice, the thinnest layer is usually $3.8 \mathrm{~cm}$ (1.5 in) or greater.

Fastener patterns and densities were calculated based on a wind uplift requirement of $5.746 \mathrm{kPa}\left(120\right.$ pounds/ $\left./ \mathrm{ft}^{2}\right)$, a $0.64 \mathrm{~mm}$ (22 ga.) metal deck, and a $1.52 \mathrm{~mm}$ (60 mil) single-ply thermoplastic membrane having a width of $3.05 \mathrm{~m}$ $(10 \mathrm{ft})$. The roof assemblies, shown in order for each case considered, are described in Table 1.

\subsection{Description of Membrane Attachment Methods}

The membrane mechanical attachment assumed standard \#15 fasteners $(0.79 \mathrm{~cm}$ diameter) and $6.03 \mathrm{~cm} \mathrm{(2-3/8} \mathrm{in)} \mathrm{diameter} \mathrm{plates,} \mathrm{installed} 15.2 \mathrm{~cm}$ (6 in.) on center for the thermal modeling work. Note that previous work assumed $0.55 \mathrm{~cm}$ diameter (\#12) fasteners for consistency with the studies by Olson, Saldanha, and Hsu and Singh, Gulati, Srinivasan, and Bhandari. However, the intent was to calculate costs more accurately for this study. Since the \#15 screw is thicker than the \#12 used previously it will likely allow for more heat transfer, thereby decreasing the effective insulation of the assembly beyond those indicated herein. 


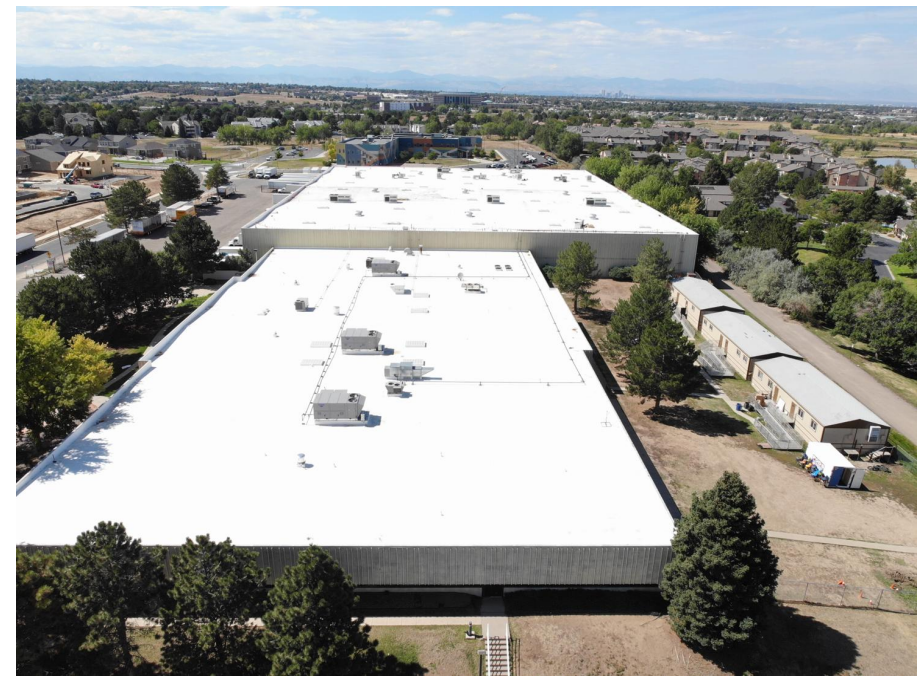

Figure 6. Examples of big box construction, with a reflective roof membrane (Image courtesy of R \& R construction, LLC, Denver, CO).

Table 1. Description of roofing assemblies analyzed in this study.

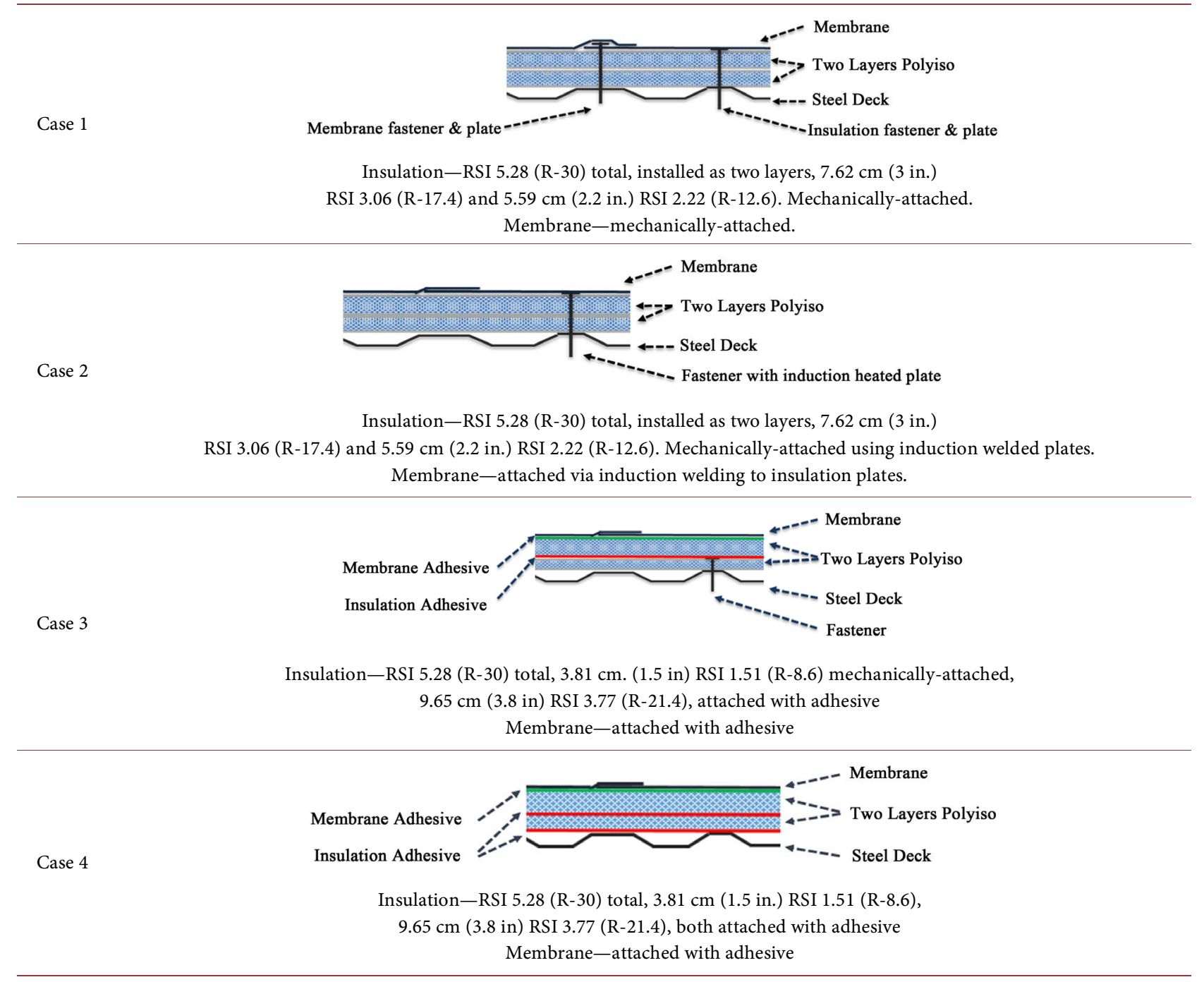


Therefore, the lost R-values (RSI) calculated in this study are likely to be conservative and actual losses could be higher. For insulation attachment, the fasteners were assumed to be the standard \#12 fasteners with $7.62 \mathrm{~cm}$ (3 in.) diameter plates.

The membrane attachment method for each case is summarized in Table 2.

For Case 1, to meet the wind uplift requirements described earlier, the field had a total of 21,372 fasteners and the perimeter and corners had a total of 8652 fasteners. Thus the overall fastener density, for both membrane and insulation, was $4.26 / \mathrm{m}^{2}\left(0.396 / \mathrm{ft}^{2}\right)$.

For Case 2, inductively-heated plates were used, where screws provide both insulation and membrane attachment. For this case, to meet the wind uplift requirements described earlier, the field had a total of 27,743 fasteners and the perimeter and corners had a total of 6634 fasteners. Thus, the overall fastener density was $2.96 / \mathrm{m}^{2}\left(0.275 / \mathrm{ft}^{2}\right)$ for both the membrane and insulation fasteners. Figure 7 shows an example of such an installation.

For Case 3, the membrane and top layer of insulation were adhered. The bottom layer of insulation was attached using 27,743 fasteners in the field and the perimeter and corners had a total of 5308 fasteners. Thus, the overall fastener density was $2.84 / \mathrm{m}^{2}\left(0.264 / \mathrm{ft}^{2}\right)$ Case 3 represents a situation where the fasteners that cause thermal bridging are themselves insulated by the top layer of insulation, thus limiting the thermal losses.

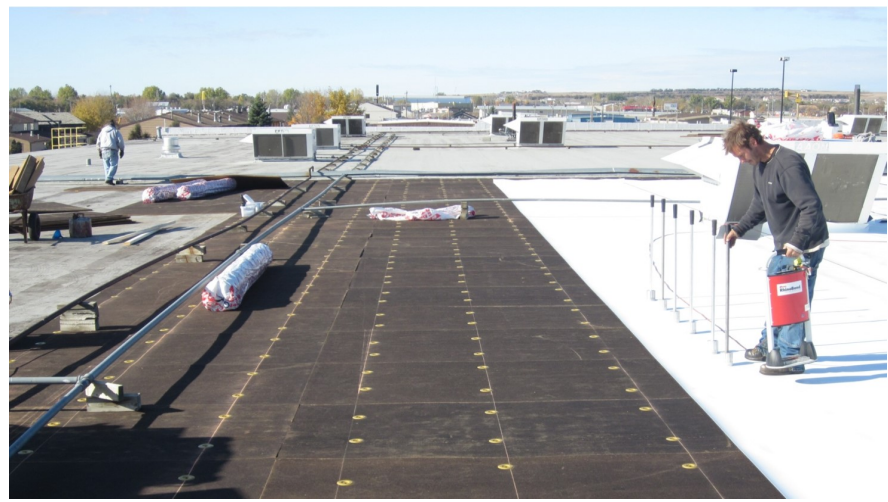

Figure 7. Attachment of a thermoplastic single ply membrane using inductively heated plates. The installer is holding the heating machine, while placing weighted magnets onto the membrane above plates that have been heated. The magnets apply pressure between the plates and the membrane to promote fusing of the two.

Table 2. Summary of membrane attachment methods.

\begin{tabular}{ccl}
\hline Assembly & Attachment Type & \multicolumn{1}{c}{ Description } \\
\hline Case 1 & Mechanical & Screws and plates along membrane seam \\
Case 2 & Induction Welding & $\begin{array}{l}\text { Coated insulation plates, inductively heated at installation } \\
\text { Case 3 }\end{array}$ \\
Case 4 & Adhered I & $\begin{array}{l}\text { Membrane and top insulation layer adhered. Screws and } \\
\text { plates for bottom insulation layer }\end{array}$ \\
\hline
\end{tabular}


Case 4 represents the design intent, whereby the specified insulation value is not compromised by thermal bridging. Note that adhering insulation directly to a steel deck is not normally considered code compliant with respect to wind uplift resistance, but is included here for comparison purposes to represent an ideal.

The insulation fastener densities (i.e. use rates), per $122 \times 244 \mathrm{~cm}(4 \times 8 \mathrm{ft})$ polyiso board, are summarized in Table 3.

\subsection{Total Fastener Densities}

The overall roof fastener densities were calculated to be as shown in Table 4.

\subsection{Labor Costs}

Mechanically-attached systems account for approximately $75 \%$ of thermoplastic single-ply roof installations [12]. Their associated labor costs are easier to estimate compared to adhered systems. With adhesive application, there are many variables such as solvent flash-off time, coverage rate, type of adhesive, and application temperature that affect application times and therefore labor costs. By timing the installation of mechanically-attached system, it was possible to estimate costs.

During installation of large single-ply roof roofs, there is a significant overlap between different phases. For example, once sufficient insulation has been installed, membrane installation begins while insulation installation continues. For this study, the costs associated with details such as parapet walls and penetration flashings were ignored since they can be expected to be the same or very similar, regardless of how the rest of the roof is installed.

Table 3. Insulation fastener usage, per $122 \times 244 \mathrm{~cm}(4 \times 8 \mathrm{ft})$ polyiso board.

\begin{tabular}{cccc}
\hline & \multicolumn{3}{c}{ Roof Zone, Fastener per Polyiso Board } \\
\cline { 2 - 4 } Assembly & Field & Perimeter & Corner \\
\hline Case 1 & 5 & 5 & 5 \\
Case 2 & 8 & 15 & 20 \\
Case 3 & 8 & 12 & 16 \\
Case 4 & 0 & 0 & 0 \\
\hline
\end{tabular}

Table 4. Overall fastener densities, including both insulation and membrane fasteners, calculated as number per unit of roof area.

\begin{tabular}{ccc}
\hline Assembly & Fastener Density per $\mathrm{ft}^{2}$ & Fastener Density per $\mathrm{m}^{2}$ \\
\hline Case 1 & 0.3964 & 4.2673 \\
Case 2 & 0.2750 & 2.9602 \\
Case $3^{*}$ & 0.2644 & 2.8463 \\
Case 4 & 0 & 0 \\
\hline
\end{tabular}

${ }^{*}$ Fasteners only used for bottom layer of insulation. 
By timing a range of big box roof installations, this study estimated that a crew of six would complete an $11,613 \mathrm{~m}^{2}\left(125,000 \mathrm{ft}^{2}\right)$ project in about 10 days. Assuming a fully burdened labor cost of $40.00 \mathrm{USD} / \mathrm{hr}$, this equates to a labor cost of 19,200 USD. It is recognized that labor rates will vary according to location, skill levels, and experience. Also, some contractors use smaller but more experienced crews while others use larger but possibly less experienced crews. Similarly, an installation of the same size using inductively-heated fastener plates would be completed in 12.5 days and therefore have a labor cost of 24,000 USD. This analysis is not intended to provide labor cost targets but to enable comparisons to be made between different attachment methods. Costs such as supervision, material delivery, and staging of materials on the job site have been assumed to be fixed regardless of application approach and have therefore been omitted from this study.

\subsection{Building Heating and Cooling Energy-Use Modeling}

Energy costs were modeled for the eight US cities using the CoolCalcPeak calculator, published by DOE/ORNL [13]. Details of validation and inputs required have been described previously [5] [6].

CoolCalcPeak makes no assumption as to building geometry. It only calculates energy loads on a building due to reflectance, emissivity, and insulation values, as well as local climate factors (discussed previously, together with the model limitations [5] [6]).

\subsection{Utility Cost Data}

Yearly average electric and gas costs for commercial customers from online databases for the latest year such data was available, 2017, were used [14] and [15] respectively. All energy costs are shown in Table A1.

As shown in a survey of utilities carried out by the National Renewable Energy Laboratory (NREL), electric demand charge rates vary considerably across utilities, locations, building sizes, and building types [16]. Demand charges often represent from $30 \%-70 \%$ of a commercial electric bill because of air conditioning use. Energy costs were analyzed for demand charges of 0 USD, 5 USD, 15 USD, and 25 USD per $\mathrm{kW}$ and were assumed to apply year round.

The energy savings due to differences between design and effective R-values were calculated as described previously [5] [6]. A building air conditioning coefficient of performance of 2.5 and a gas heating efficiency of 0.8 were used. These are representative of newer equipment.

\section{Results}

These costs associated with a specified roof design based on RSI 5.28 (R-30) and the resulting effective RSI due to attachment methodology were evaluated. Such costs include the lost economic value of purchased RSI that was not achieved due to thermal bridging. 


\subsection{Loss of Insulation Value Due to Fasteners}

The fastener densities shown in Table 4, together with the relationship between fastener density and percent reduction in RSI, were used to determine the effective RSI and the percent reductions versus an RSI 5.28 (R-30) design which are as shown in Table 5.

The effective RSI (R-value) is significantly lower than the design RSI5.28 (R-30) for Cases 1 and 2. For Case 3, with a $3.8 \mathrm{~cm}$ (1.5 in) bottom layer of mechanically-attached polyiso and a second layer adhered, a small reduction in insulation value was obtained. The values shown in Table 5 are an average. In practice, thermal losses will be higher in those areas with greater fastener densities such as corners and perimeters, versus those areas with lesser fastener densities such as the field of the roof.

\subsection{Cost of Fasteners and Lost Insulation Value}

As described earlier, roofing assembly specifications include a designed thermal resistance value, assumed to be RSI 5.28 (R-30) for this study. However, the practical construction of such an assembly is often achieved solely with mechanical fasteners. The cost of these, together with the value of the lost thermal resistance due to bridging, is shown in Table 6 for Cases 1, 2, and 3. Note that Case 4 did not have any mechanical fasteners and was therefore assumed to meet the designer's intent for insulation value. The lost RSI was calculated in terms of US dollars per RSI lost, i.e., purchased material that did not contribute to insulation, using the percent reductions shown in Table 5. For the standard polyiso boards, a material-based cost to the building owner about $4.89 \mathrm{USD} / \mathrm{m}^{2} / \mathrm{RSI} 1(0.08$ $\mathrm{USD} / \mathrm{ft}^{2} / \mathrm{R}-1$ ) was assumed.

The largest insulation cost in lost RSI was for the fully mechanically-attached Case 1, being 44,757 USD.

Table 5. Effective RSI (R-values) for each of the modeled assemblies, based on an RSI 5.28 (R-30) design.

\begin{tabular}{cccc}
\hline Assembly & Effective R-value & Effective RSI & Reduction in RSI (R-value) \\
\hline Case 1 & 25.658 & 4.519 & $14.47 \%$ \\
Case 2 & 26.526 & 4.672 & $11.58 \%$ \\
Case 3 & 29.032 & 5.113 & $3.23 \%$ \\
Case 4 & 30.000 & 5.283 & $0 \%$ \\
\hline
\end{tabular}

Table 6. Assembly attachment costs due to mechanical fasteners and the economic value of reduction from design to effective insulation value.

\begin{tabular}{cccc}
\hline Assembly & Fasteners, USD & Cost of Lost RSI, USD & Total (USD) \\
\hline Case 1 & 15,633 & 44,757 & 60,391 \\
Case 2 & 19,217 & 35,802 & 55,019 \\
Case 3 & 5189 & 9981 & 15,170 \\
Case 4 & 0 & 0 & 0 \\
\hline
\end{tabular}




\subsection{Lost Energy Efficiency Due to Fasteners}

The effective R-values from Table 6 were used to calculate the cost of a building's reduced energy efficiency relative to the design RSI 5.28 (R-30) over a 15 -year time frame. This was chosen due to the published polyiso foam RSI (R-value) representing the time weighted 15-year long-term thermal resistance [17] [18]. The results are summarized in Table A2 and show that the opportunity to provide savings by reducing thermal bridging occurs when demand charges are highest.

\subsection{Target Installation Costs for Case 3-0pportunity for Reducing Thermal Bridging}

By adding the mechanical fastener and labor costs to those of the lost insulation value and degraded energy efficiency, it is possible to calculate target installation costs for low or zero thermal bridging systems. Case 3 represents an installation that relies on mechanical attachment of the bottom insulation layer but all subsequent layers would be adhesively-attached. The labor and material costs of such an application are shown in Table 7.

\subsection{Target Installation Costs for Case 4-0pportunity for Eliminating Thermal Bridging}

Case 4 represents a scenario that achieves the insulation value intended by the specifier, i.e. installation such that thermal bridging doesn't occur. This would entail the use of adhesive attachment for each layer, including the bottom layer of insulation to the roof deck. The target labor and material costs of such an application are shown in Table 8.

\section{Discussion}

The thermal insulation losses caused by metal fasteners are very significant, ranging between a high of about $14.5 \%$ for the traditional system to about $11.5 \%$ for the inductively-heated plates type.

Table 7. Labor and adhesive material cost targets for Case 3.

\begin{tabular}{ccccc}
\hline & \multicolumn{4}{c}{ Case 3 Adhesive \& Labor Target, USD } \\
\cline { 2 - 5 } Demand Charge, USD/kW & 0 & 5 & 15 & 25 \\
\hline Albany, NY & 76,276 & 76,276 & 78,151 & 81,901 \\
Chicago, IL & 76,276 & 76,276 & 80,026 & 80,026 \\
Fresno, CA & 78,151 & 80,026 & 81,901 & 83,776 \\
Fort Worth, TX & 78,151 & 78,151 & 81,901 & 83,776 \\
Miami, FL & 78,151 & 80,026 & 81,901 & 85,651 \\
Nashville, TN & 76,276 & 78,151 & 80,026 & 83,776 \\
Newark, NJ & 74,430 & 76,276 & 78,151 & 78,151 \\
Portland, OR & 74,401 & 74,401 & 78,151 & 80,026 \\
\hline
\end{tabular}


Table 8. Labor and adhesive material cost targets for Case 4.

\begin{tabular}{ccccc}
\hline \multirow{2}{*}{ Demand Charge, USD/kW } & \multicolumn{4}{c}{ Case 4 Adhesive \& Labor Target, USD } \\
\cline { 2 - 5 } & 0 & 5 & 15 & 25 \\
\hline Albany, NY & 81,465 & 81,465 & 83,340 & 87,090 \\
Chicago, IL & 81,465 & 81,465 & 85,215 & 85,215 \\
Fresno, CA & 83,340 & 85,215 & 87,090 & 88,965 \\
Fort Worth, TX & 83,340 & 83,340 & 87,090 & 88,965 \\
Miami, FL & 83,340 & 85,215 & 87,090 & 90,840 \\
Nashville, TN & 81,465 & 83,340 & 85,215 & 88,965 \\
Newark, NJ & 79,619 & 81,465 & 83,340 & 83,340 \\
Portland, OR & 79,590 & 79,590 & 83,340 & 85,215 \\
\hline
\end{tabular}

The economic costs of the lost insulation value are significant. As shown, the mechanically-attached roof system with two layers of polyiso insulation loses a little over 45,000 USD in purchased RSI(R-value) for the 11,613 $\mathrm{m}^{2}\left(125,000 \mathrm{ft}^{2}\right)$ roof assumed here.

By factoring in the costs of mechanical attachment, labor plus materials, lost long-term energy efficiency, and the loss of RSI (R-value) that was purchased but not obtained due to thermal bridging, the study shows that:

- For a system with a bottom layer of polyiso mechanically-attached to the steel deck, and all subsequent layers adhered, the cost "available" to use adhesives ranges from approximately 74,400 to 83,800 USD depending on location and the level of demand charges. This was represented by Case 3 in this study.

- For a system with every layer adhered, the cost "available" to use adhesives ranges from approximately 79,600 to 90,800 USD depending on location and the level of demand charges. This was represented by Case 4 in this study.

This study considered an 11,613 $\mathrm{m}^{2}\left(125,000 \mathrm{ft}^{2}\right)$ big box type of building. For similar buildings, the cost targets would be:

- For the bottom layer of polyiso being mechanically-attached and subsequent layers being adhered, the target adhesive material and labor cost would range between 64.05 and $72.12 \mathrm{USD} / \mathrm{m}^{2}$ (59.50 and $67.00 \mathrm{USD} / 100 \mathrm{ft}^{2}$ ).

- For a system that was totally adhered, the target adhesive material and labor cost would range between 68.51 and $78.20 \mathrm{USD} / \mathrm{m}^{2}$. (63.65 and 72.65/100 $\left.\mathrm{ft}^{2}\right)$.

Such cost targets are based on a fully burdened labor rate of $40 \mathrm{USD} / \mathrm{hr}$ and should be scaled accordingly for actual rates based on location, crew skill level and experience etc. Also, the analysis did not take into account roofing equipment costs. For example, adhesive systems can require sprayers and other types of applicators, the costs of which would need to be amortized across multiple jobs. In the US, some manufacturers have introduced TPO membranes with 3.6 $\mathrm{m}(12 \mathrm{ft})$ width. Such a width allows for lower cost installation due to reduced numbers of seams, but can also be advantageous with inductively heated plate application and for adhered systems. This could change the analysis shown here. 
This study evaluated the thermal bridging drawbacks of mechanical attachment by factoring in all of the impacts of lost insulation value and provided cost targets for adhered systems. However, there are other benefits to adhered systems, including the following:

- Adhered systems do not flutter or billow during high wind events, thereby eliminating the drawing up of interior conditioned air up into the roof assembly (e.g., infiltration). This latter phenomenon would naturally further reduce energy efficiency (see Pallin, Kehrer, and Desjarlais [19] and Molleti et al. [20] for examples).

- Adhered systems have higher wind uplift strengths, so this may provide options in some areas of the country and projects requiring increased uplift design requirements.

- Elimination of localized cold spots in the steel deck, caused by metal fasteners. These cold spots could cause condensation issues depending on climate and building usage.

\section{Conclusion}

This study was a modeling exercise to evaluate the cost targets necessary to reduce or minimize the cost of thermal bridging caused by metal fasteners in low-slope single-ply roofing assemblies. As was shown, thermal bridging of roof assemblies incurs costs associated with lost insulation value and reduced long term energy efficiency. By modeling these costs together with the labor costs incurred during roof installation it was possible to estimate the break-even point. In other words, the costs associated with adhering roof materials instead of mechanically fastening them. This data could be used to refine product development in the roofing market for adhesives with cost and labor.

\section{Conflicts of Interest}

The author declares no conflicts of interest regarding the publication of this paper.

\section{References}

[1] US Energy Information Administration. https://www.eia.gov/energyexplained/use-of-energy/commercial-buildings.php

[2] IEA (2013) Transition to Sustainable Buildings: Strategies and Opportunities to 2050. OECD, IEA, Paris, France.

[3] Building Envelope Thermal Bridging Guide (2016) BC Hydro Power Smart, Version 1.1 .

https://www.bchydro.com/content/dam/BCHydro/customer-portal/documents/po wer-smart/builders-developers/building-envelope-thermal-bridging-guide-1.1.pdf

[4] Taylor, T.J. (2019) Reflective Roofing Use on Commercial Buildings in the United States: An Energy Type and Cost Analysis. Buildings, 9, 212. https://doi.org/10.3390/buildings9100212

[5] Taylor, T.J., Willits, J., Hartwig, C.A. and Kirby, J.R. (2018) Optimizing Low-Slope 
Roofing Assemblies for Insulation Value. Buildings, 8, 64. https://doi.org/10.3390/buildings8050064

[6] Taylor, T.J., Willits, J., Hartwig, C.A. and Kirby, J.R. (2018) Insulation Value Optimization for Low-Slope Roofs. Building Envelope Technology Symposium.

[7] Burch, D.M., Shoback, P.J. and Cavanaugh, K. (1987) A Heat Transfer Analysis of Metal Fasteners in Low-Slope Roofs. In: Roofing Research and Standards Development, ASTM International, West Conshohocken, PA, 10-22. https://doi.org/10.1520/STP25721S

[8] Olson, E.K., Saldanha, C.M. and Hsu, J.W. (2015) Thermal Performance Evaluation of Roofing Details to Improve Thermal Efficiency and Condensation Resistance. In: Molleti, S. and Rossiter, W.J., Eds., Roofing Research and Standards Development, Volume 8, ASTM International, West Conshohocken, PA, 10-22. https://doi.org/10.1520/STP159020150021

[9] Singh, M., Gulati, R., Srinivasan, R.S. and Bhandari, M. (2016) Three-Dimensional Heat Transfer Analysis of Metal Fasteners in Roofing Assemblies. Buildings, 6, 49. https://doi.org/10.3390/buildings6040049

[10] Cool Roof Rating Council. http://coolroofs.org/products/results

[11] 2018 International Energy Conservation Code, International Code Council. https://codes.iccsafe.org/content/iecc2018/toc

[12] GAF Internal Sales Data for 2018.

[13] ORNL Cool Roof Calculator with Peak Demand. http://web.ornl.gov/sci/buildings/tools/cool-roof/peak/

[14] Eisenbach Consulting. https://www.electricchoice.com/electricity-prices-by-state/

[15] US Energy Information Administration, https://www.eia.gov/dnav/ng/ng_pri_sum_dcu_nus_a.htm

[16] NREL https://www.nrel.gov/docs/fy17osti/68963.pdf

[17] Polyiso Manufacturers Association. http://www.polyiso.org/?page=LTTRQM

[18] Cusick, M., Wang, L. and Griffin, C. (2014) New LTTR Values and What They Mean for Roofing Industry Professionals. Roofing Contractor, Troy, MI.

[19] Pallin, P., Kehrer, M. and Desjarlais, A. (2014) The Energy Penalty Associated With the Use of Mechanically Attached Roofing Systems. Proceedings of the Symposium on Building Envelope Technology, Tampa, FL, 20-21 October 2014.

[20] Molleti, S., Baskaran, B., Kalinger, P., Graham, M., Cote, J.F., Malpezzi, J. and Schwetz, J. (2015) Evaluation of Air Leakage Properties of Seam-Fastened Mechanically Attached Single-Ply and Polymer-Modified Bitumen Roof Membrane Assemblies. In: Molleti, S. and Rossiter, W.J., Eds., Roofing Research and Standards Development, Volume 8, ASTM International, West Conshohocken, PA, 30-43. https://doi.org/10.1520/STP159020150025 


\section{Appendix A}

Table A1. Climate and energy cost data used for the annual savings modeling.

\begin{tabular}{|c|c|c|c|c|c|c|c|c|c|}
\hline \multirow{2}{*}{ City, State } & \multirow{2}{*}{$\begin{array}{c}\text { ASHRAE } \\
\text { Climate } \\
\text { Zone }\end{array}$} & \multirow{2}{*}{$\begin{array}{c}\text { CoolCalcPeak } \\
\text { HDD }\end{array}$} & \multirow{2}{*}{$\begin{array}{l}\text { CoolCalcPeak } \\
\text { CDD }\end{array}$} & \multirow{2}{*}{$\begin{array}{l}\text { HDD } \\
2017\end{array}$} & \multirow{2}{*}{$\begin{array}{l}\text { CCD } \\
2017\end{array}$} & \multirow{2}{*}{$\begin{array}{c}\text { Electric } \\
\text { Cost } 2017 \\
\text { USD/kWh }\end{array}$} & \multicolumn{3}{|c|}{ Gas Cost 2017} \\
\hline & & & & & & & $\mathrm{USD} / 1000 \mathrm{ft}^{3}$ & USD/Therm & $\mathrm{USD} / 100 \mathrm{~m}^{3}$ \\
\hline Albany, NY & $5 \mathrm{~A}$ & 7083 & 542.5 & 5983 & 714 & 0.1876 & 6.87 & 0.687 & 24.261 \\
\hline Chicago, IL & $5 \mathrm{~A}$ & 6449.5 & 748.5 & 5631 & 799 & 0.1295 & 7.78 & 0.778 & 27.475 \\
\hline Miami, FL & $1 \mathrm{~A}$ & 141 & 4126.5 & 45 & 5287 & 0.1202 & 10.97 & 1.097 & 38.740 \\
\hline Fresno, CA & $3 \mathrm{~B}$ & 2601.5 & 1883.5 & 1926 & 2489 & 0.1939 & 8.76 & 0.876 & 30.936 \\
\hline Nashville, TN & $4 \mathrm{~A}$ & 4031.5 & 1672 & 2745 & 1925 & 0.1093 & 8.74 & 0.874 & 30.865 \\
\hline Newark, NJ & $4 \mathrm{~A}$ & 5122.5 & 1061.5 & 4330 & 1316 & 0.1596 & 9.14 & 0.914 & 32.278 \\
\hline Portland, OR & $4 \mathrm{C}$ & 4461 & 278.5 & 4559 & 700 & 0.1097 & 8.74 & 0.874 & 30.865 \\
\hline Fort Worth, TX & $3 \mathrm{~A}$ & 2304 & 2414.5 & 1427 & 3206 & 0.1115 & 7.71 & 0.771 & 27.228 \\
\hline
\end{tabular}

Table A2. Total 15-year cost of lost energy efficiency due to the effective R-values compared to the design R-30, all values being USD, assuming gas heat. Three-year aged membrane reflectance and emissivity values were used.

\begin{tabular}{|c|c|c|c|c|c|c|c|c|c|c|c|c|}
\hline \multirow{2}{*}{ Demand Charge, USD/kW } & \multicolumn{4}{|c|}{ Case 1} & \multicolumn{4}{|c|}{ Case 2} & \multicolumn{4}{|c|}{ Case 3} \\
\hline & 0 & 5 & 15 & 25 & 0 & 5 & 15 & 25 & 0 & 5 & 15 & 25 \\
\hline Chicago, IL & 1875 & 5625 & 15,000 & 20,625 & 1875 & 5625 & 13,125 & 18,750 & 1875 & 1875 & 5625 & 5625 \\
\hline Fresno, CA & 11,250 & 16,875 & 24,375 & 33,750 & 11,250 & 15,000 & 20,625 & 28,125 & 3750 & 5625 & 7500 & 9375 \\
\hline Fort Worth, TX & 7500 & 11,250 & 20,625 & 30,000 & 7500 & 9375 & 18,750 & 24,375 & 3750 & 3750 & 7500 & 9375 \\
\hline Miami, FL & 11,250 & 16,875 & 24,375 & 33,750 & 9375 & 13,125 & 20,625 & 30,000 & 3750 & 5625 & 7500 & 11,250 \\
\hline Nashville, TN & 5625 & 9375 & 16,875 & 26,250 & 5625 & 7500 & 15,000 & 22,500 & 1875 & 3750 & 5625 & 9375 \\
\hline Newark, NJ & 3750 & 9375 & 15,000 & 22,500 & 27 & 3750 & 7500 & 13,125 & 29 & 1875 & 3750 & 3750 \\
\hline
\end{tabular}

